\title{
Association of regular leisure-time physical activity with self-reported body mass index and obesity risk among middle-aged and older adults in Taiwan
}

\section{Yun-Tsung Chen}

National Taiwan Normal University

Po-Fu Lee

National I-Lan University

Chi-Fang Lin

National Taiwan Normal University

Andy Chang

Texas Commission on Environmental Quality

\section{Yu-Chun Chung}

Taipei Medical University

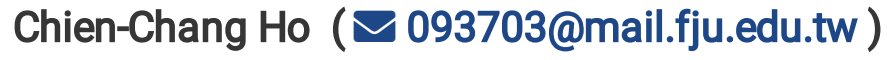

Fu Jen Catholic University https://orcid.org/0000-0002-1283-5203

\section{Research}

Keywords: physically inactive, obese, underweight, health status

Posted Date: July 26th, 2021

DOl: https://doi.org/10.21203/rs.3.rs-729978/v1

License: (9) (i) This work is licensed under a Creative Commons Attribution 4.0 International License. Read Full License

Version of Record: A version of this preprint was published at Healthcare on December 13th, 2021. See the published version at https://doi.org/10.3390/healthcare9121719. 


\section{Abstract \\ Background}

Through this study, we aimed to determine the association of regular leisure-time physical activity (LTPA) with self-reported body mass index (BMI) and obesity risk among middle-aged and older adults in Taiwan.

\section{Methods}

We conducted a cross-sectional study and reviewed the data derived from the Taiwan's National Physical Activity Survey (TNPAS). Responses from 12,687 participants aged 45-108 years from the database were collected in this study. All participants completed a standardized, structured questionnaire that solicitated information regarding their demographic characteristics (age, gender, education, occupation, and self-reported health status), physical activity behaviors (regular/nonregular LTPA), and self-reported anthropometrics (height, weight, and BMI). Multiple linear and logistic regression were used to examine the association between regular LTPA and BMI as well as between regular LTPA and obesity status, respectively.

\section{Results}

Regular LTPA was associated with a male preponderance, normal weight, excellent or good self-reported health status, and a lower rate of underweight compared with nonregular LTPA. Regular LTPA was significant negatively associated with underweight $(O R=0.71, p<0.05)$, whereas it had no significant relationship with $\mathrm{BMI}$ and obesity $(p>0.05)$.

\section{Conclusions}

Regular LTPA was associated with a reduced risk of underweight among middle-aged and elderly adults in Taiwan. Further research on the relevant mechanism underlying this phenomenon is warranted.

\section{Background}

According to the World Health Organization (WHO), the global prevalence of obesity nearly tripled since 1975, and approximately 13\% (over 650 million) of adults worldwide were classified as obese in 2016 [1]. Obesity is defined as a body mass index (BMI) greater than or equal to $30 \mathrm{~kg} / \mathrm{m}^{2}$, and it may increase the risk of developing coronary heart disease, hypertension, type 2 diabetes, sleep apnea, osteoarthritis, and some cancers [2]. However, Gurrici et al. suggested that the cut-off point for obesity based on BMI in 
Asian individuals should be $27 \mathrm{~kg} / \mathrm{m}^{2}$, as Asian individuals with the same age, gender, and body fat percentage have an approximately $3 \mathrm{~kg} / \mathrm{m}^{2}$ lower BMI compared with Caucasian individuals [3].

Physical activity (PA) is recommended as an important part of weight management for enhancing weight loss and preventing weight regain [4]. Moreover, PA is associated with a decreased risk of cardiovascular disease (CVD), stroke, diabetes, metabolic syndrome, and cancers (e.g., colon and breast cancers) $[4,5]$. The American College of Sports Medicine (ACSM) recommends that adults with overweight or obesity should perform moderate-intensity PA for $\geq 150$ minutes/week to improve their health, and a progressive increase to 200-300 minutes/week was recommended for long-term weight loss [6]. However, $31 \%$ of adults (especially older adults) worldwide are physically inactive, leading to approximately 3 million deaths per year and costing global healthcare systems approximately US\$50 [7, 8].

According to the WHO, the terms "aging society" and "aged society" refer to societies with $\geq 7 \%$ and $\geq$ $14 \%$ of individuals aged $\geq 65$ years, respectively [9]. Taiwan was considered an aging society in 1993 and became an aged society in 2018 [10]. It is estimated that in 2026, Taiwan will enter the era of a "superaged society," where the proportion of elderly adults would be $\geq 20 \%$ [11]. Therefore, successful aging is an important issue in Taiwan for individuals to reduce the risk of chronic disease and disability, maintain physical and cognitive function, and sustain active engagement with life [12].

Numerous studies have found that older adults who participated in leisure-time physical activity (LTPA) had a reduced risk of many chronic diseases and increased physical and cognitive function as well as improved quality of life $[13,14]$. However, relatively limited information is available regarding the relationship between LTPA and body mass index (BMI) and obesity risk with consideration for the health status, education, and occupation factors of middle-aged and elderly adults in Taiwan. Therefore, through the present study, we aimed to investigate the association of regular LTPA with self-reported BMI and obesity risk and the determining factors that influence this relationship among middle-aged and older adults in Taiwan.

\section{Methods}

\section{Study design and participants}

We performed a cross-sectional observational study using nationally representative data regarding middle-aged and older adults (age range, 45-108 years) from the Taiwan's National Physical Activity Survey (TNPAS) conducted by the Taiwan's Sports Administration, Ministry of Education. Recruitment was conducted through random-digit dialing of the numbers of the proportionally stratified sample by age, gender, and geographical districts; the detailed procedure has been described elsewhere (Ku et al., 2006). The participants were citizens aged over 13 years and stratified by 22 cities/counties across Taiwan. The sample size of each city/county was calculated by its proportion to Taiwan's population. The total sample size was 25,526 in 2020 , with sampling errors equal to or less than $5 \%$ and confidence intervals (Cls) of $95 \%$, which provided sufficient sample size and statistical power. Subsequently, a 
computer-assisted telephone interview (CATI) survey was conducted from August to October 2020. Welltrained and experienced interviewers were employed in the CATI survey to ensure the quality of data collection. Data collected from the telephone survey questionnaire included information on sociodemographic characteristics (age, gender, education, occupation, and zip code of residence), LTPA behaviors, and self-evaluations (including health status and anthropometric variables [height and body weight]). Finally, 12,687 participants were enrolled into this study. This study was conducted in accordance with the Declaration of Helsinki, and all procedures were in accordance with the ethical standards of the Institutional Review Board of Fu Jen Catholic University in Taiwan (FJU- IRB C109085). Oral consent was provided by the participants before telephonic interviews.

\section{Data collection}

Sociodemographic characteristics such as age, gender, education, occupation, and zip code of residence; LTPA behaviors; and self-evaluations such as health status and anthropometrics variables (height and body weight) of the participants were recorded. The participants were divided into five groups according to their age $(45-49,50-54,55-59,60-64$, and $\geq 65$ years). Education was categorized into three levels (elementary school or lower, junior or senior high school, and college or higher). Occupation was categorized into 11 categories (white collar, government servant, blue collar, owner/manager, specialists, student, housewife, retired, freelancer, jobless, and other). Self-reported health status was categorized into three levels (excellent or good, fair, and very bad or poor).

\section{Anthropometric variables and obesity status}

Anthropometric variables such as height and body weight were obtained from the CATI survey, and BMI $\left(\mathrm{kg} / \mathrm{m}^{2}\right)$ was further calculated. Then, BMI cut-off points were adopted as suggested by the Health Promotion Administration, Ministry of Health and Welfare in Taiwan including underweight $(\mathrm{BMI}<18.5$ $\left.\mathrm{kg} / \mathrm{m}^{2}\right)$, normal weight $\left(18.5 \mathrm{~kg} / \mathrm{m}^{2} \leq \mathrm{BMl}<24 \mathrm{~kg} / \mathrm{m}^{2}\right)$, overweight $\left(24 \mathrm{~kg} / \mathrm{m}^{2} \leq \mathrm{BMl}<27 \mathrm{~kg} / \mathrm{m}^{2}\right)$, and obesity (BMI $\geq 27 \mathrm{~kg} / \mathrm{m}^{2}$ ) categories (Ministry of Health and Welfare, 2021).

\section{LTPA assessment}

The LTPA of the participants was assessed by a series of questions during the CATI survey. First, the participants were asked to describe their current LTPA participation. The question was as follows: "Have you participated in any LTPA in the past month?" Respondents who responded "yes" were then asked to note the frequency and duration of their participation in LTPA, with questions such as "How many times do you participate in LTPA per week?" and "How many minutes do you usually spend at one time?" Further, the intensity of LTPA was assessed based on the breathing and sweating status of the participants, through the question "When you are doing LTPA, you usually feel...." The participants chose their response from structural answers such as "no changes in my breath and sweating," "I breathe faster but do not sweat," "I breathe normally but sweat," and "I breathe quickly and sweat." Participants who reported that they usually breathed quickly and sweated were thus considered to engage in moderateintensity LTPA. Thus, participants were dichotomized into regular and non-regular LTPA groups according to the physical activity (PA) recommendations specified in WHO guidelines. First, participants who 
reported performing 150-300 minutes of moderate-intensity LTPA or 75-150 minutes of vigorousintensity LTPA per week and responded "yes" to breathing quickly and sweating were classified into the regular LTPA group. The rest of the participants were categorized as the non-regular LTPA group.

\section{Statistical analysis}

Data were analyzed using SAS 9.4 (SAS Institute, Cary, NC, USA). Student's $t$-test was performed to analyze continuous variables, and the chi-square test was used to analyze categorical variables. Multiple linear regression analysis with $\mathrm{BMI}$ as the dependent variable was used to examine the association of regular LTPA with BMI after adjustment for potential confounders. Adjusted odds ratios (ORs) with $95 \%$ Cls for obesity, overweight, or underweight were calculated from unconditional logistic regression models according to regular LTPA. Values are presented as means \pm standard deviation or frequency percentages. Results were considered two-tailed and statistically significant at $p<0.05$.

\section{Results}

A total of 12,687 participants were dichotomized into regular and nonregular LTPA groups based on their LTPA status. Their sociodemographic characteristics and anthropometric variables are presented in Table 1. All participants were divided into dichotomous groups, namely regular LTPA and nonregular LTPA groups; the nonregular LTPA group had a large proportion (79\%) of participants. Except for BMI ( $p=$ 0.063), significant differences were observed between the groups $(p<0.05)$ in terms of all relevant variables, including age, gender, height, body weight, BMI, obesity status, education, occupation, and selfreported health status $(p<0.05)$. The regular LTPA group had a higher proportion of men $(53.3 \%)$, higher proportion of normal-weight individuals (48.8\%), and a higher education rate (27\% of the participants had completed college education); almost $34.9 \%$ of the participants had already retired, and $75.5 \%$ selfreported that they were in excellent or good health. 
Table 1

Demographic characteristics of the participants

\begin{tabular}{|c|c|c|c|}
\hline \multirow[t]{3}{*}{ Variables } & \multicolumn{2}{|l|}{ LTPA Status } & \multirow[t]{3}{*}{$P$-value } \\
\hline & Regular LTPA & Non-regular LTPA & \\
\hline & $(n=2,641)$ & $(n=10,046)$ & \\
\hline Age $(y)$ & & & $0.037 *$ \\
\hline $45-49$ & $427(16.20 \%)$ & $1655(16.50 \%)$ & \\
\hline $50-54$ & $480(18.20 \%)$ & $1647(16.40 \%)$ & \\
\hline $55-59$ & $434(16.40 \%)$ & $1721(17.10 \%)$ & \\
\hline $60-64$ & $438(16.60 \%)$ & $1525(15.20 \%)$ & \\
\hline$\geq 65$ & $862(32.60 \%)$ & 3497 (34.80\%) & \\
\hline Gender (\% men) & $1,407(53.3 \%)$ & $4,452(44.3 \%)$ & $<0.001^{\star}$ \\
\hline Height (cm) & $163.62 \pm 7.78$ & $161.92 \pm 7.95$ & $<0.001^{\star}$ \\
\hline Body weight $(\mathrm{kg})$ & $64.60 \pm 11.61$ & $62.88 \pm 11.63$ & $<0.001^{\star}$ \\
\hline $\mathrm{BMI}\left(\mathrm{kg} / \mathrm{m}^{2}\right)$ & $24.04 \pm 3.38$ & $23.90 \pm 3.46$ & 0.063 \\
\hline Obese Status (\%) & & & $<0.001^{\star}$ \\
\hline Underweight & $53(2.00 \%)$ & $310(3.10 \%)$ & \\
\hline Normal weight & $1289(48.80 \%)$ & $4805(47.80 \%)$ & \\
\hline Overweight & $770(29.20 \%)$ & $2668(26.60 \%)$ & \\
\hline Obese & $407(15.40 \%)$ & $1572(15.60 \%)$ & \\
\hline Education (\%) & & & $<0.001^{*}$ \\
\hline Elementary school or lower & $340(13.00 \%)$ & $1904(19.10 \%)$ & \\
\hline Junior or senior school & $1570(60.00 \%)$ & $6100(61.30 \%)$ & \\
\hline College or higher & $706(27.00 \%)$ & $1940(19.50 \%)$ & \\
\hline Occupation (\%) & & & $<0.001^{*}$ \\
\hline White collar & $287(10.90 \%)$ & $894(9.00 \%)$ & \\
\hline
\end{tabular}

Abbreviations: BMI, body mass index; LTPA, leisure time physical activity ${ }^{*} p<0.05$.

${ }^{a}$ Values expressed as means \pm standard deviation for continuous variables 


\begin{tabular}{|c|c|c|c|}
\hline \multirow[t]{3}{*}{ Variables } & \multicolumn{2}{|l|}{ LTPA Status } & \multirow[t]{3}{*}{$P$-value } \\
\hline & Regular LTPA & Non-regular LTPA & \\
\hline & $(n=2,641)$ & $(n=10,046)$ & \\
\hline Government servant & $161(6.10 \%)$ & $408(4.10 \%)$ & \\
\hline Blue collar & $323(12.30 \%)$ & $1931(19.40 \%)$ & \\
\hline Owner/manager & $194(7.40 \%)$ & $630(6.30 \%)$ & \\
\hline Specialists & $104(4.00 \%)$ & $353(3.50 \%)$ & \\
\hline Student & $0(0.00 \%)$ & $2(0.00 \%)$ & \\
\hline Housewife & $433(16.50 \%)$ & $2124(21.40 \%)$ & \\
\hline Retired & $917(34.90 \%)$ & $2790(28.00 \%)$ & \\
\hline Free lancer & $121(4.60 \%)$ & $445(4.50 \%)$ & \\
\hline Jobless & $69(2.60 \%)$ & $328(3.30 \%)$ & \\
\hline Other & $15(0.60 \%)$ & $42(0.40 \%)$ & \\
\hline Self-reported health status (\%) & & & $<0.001 *$ \\
\hline Excellent or good & $1967(77.50 \%)$ & $6826(71.90 \%)$ & \\
\hline Fair & $184(7.30 \%)$ & $902(9.50 \%)$ & \\
\hline Very bad or poor & $386(15.20 \%)$ & $1767(18.60 \%)$ & \\
\hline \multicolumn{4}{|c|}{ Abbreviations: BMI, body mass index; LTPA, leisure time physical activity } \\
\hline \multicolumn{4}{|l|}{${ }^{*} p<0.05$} \\
\hline
\end{tabular}

Table 2 presents the results of a comparison of BMI values between regular LTPA and nonregular LTPA status among middle-aged and older adults. Pooled data showed significant differences $(p<0.05)$ in the group of oldest ( $\geq 65$ years) participants. Participants in the regular LTPA group had higher BMI values than other groups $\left(24.01 \pm 2.91 \mathrm{~kg} / \mathrm{m}^{2}\right)$. In addition, BMI values significantly differed between regular LTPA and nonregular LTPA group among the youngest male participants (age, $45-49$ years; $p<0.05$ ). Men in the regular LTPA group had higher BMI values than those in the other group $\left(25.39 \pm 3.22 \mathrm{~kg} / \mathrm{m}^{2}\right)$. 
Table 2

Comparison of BMI values according to LTPA status among middle-aged and older adults in Taiwan

\begin{tabular}{|c|c|c|c|}
\hline \multirow[t]{2}{*}{ Variables } & \multicolumn{2}{|l|}{ LTPA Status } & \multirow[t]{2}{*}{ P-value } \\
\hline & Regular LTPA & Non-regular LTPA & \\
\hline \multicolumn{4}{|c|}{ Men $(n=5.502)$} \\
\hline $45-49$ & $25.39 \pm 3.22$ & $24.76 \pm 3.16$ & $0.015^{\star}$ \\
\hline $50-54$ & $24.44 \pm 2.65$ & $24.75 \pm 3.06$ & 0.140 \\
\hline $55-59$ & $24.73 \pm 2.84$ & $24.39 \pm 3.00$ & 0.136 \\
\hline $60-64$ & $24.54 \pm 2.44$ & $24.31 \pm 2.86$ & 0.267 \\
\hline$\geq 65$ & $24.30 \pm 2.59$ & $24.05 \pm 2.86$ & 0.073 \\
\hline \multicolumn{4}{|c|}{ Women $(n=6,153)$} \\
\hline $45-49$ & $22.43 \pm 2.29$ & $22.54 \pm 3.06$ & 0.575 \\
\hline $50-54$ & $22.79 \pm 2.73$ & $23.00 \pm 3.11$ & 0.312 \\
\hline $55-59$ & $22.71 \pm 2.92$ & $23.09 \pm 2.96$ & 0.109 \\
\hline $60-64$ & $22.99 \pm 2.91$ & $23.24 \pm 3.01$ & 0.294 \\
\hline$\geq 65$ & $23.57 \pm 3.28$ & $23.45 \pm 3.03$ & 0.529 \\
\hline \multicolumn{4}{|c|}{ Pooled $(n=11,655)$} \\
\hline $45-49$ & $23.87 \pm 3.15$ & $23.52 \pm 3.30$ & 0.058 \\
\hline $50-54$ & $23.66 \pm 2.81$ & $23.72 \pm 3.20$ & 0.717 \\
\hline $55-59$ & $23.76 \pm 3.05$ & $23.66 \pm 3.05$ & 0.587 \\
\hline $60-64$ & $23.80 \pm 2.78$ & $23.73 \pm 2.99$ & 0.665 \\
\hline$\geq 65$ & $24.01 \pm 2.91$ & $23.74 \pm 2.96$ & $0.024^{\star}$ \\
\hline \multicolumn{4}{|c|}{ Abbreviations: BMI, body mass index; LTPA, leisure time physical activity } \\
\hline${ }^{\star} p<0.05$ & & & \\
\hline
\end{tabular}

The results of the comparison between the prevalence of obesity status and LTPA status among middleaged and older adults are shown in Table 3. With regard to obesity status, significant differences between regular LTPA and nonregular LTPA groups were found only in the underweight group in pooled data ( $p<$ $0.05)$ in the group of participants aged $50-54$ years. A higher prevalence $(4.00 \%)$ of underweight was observed in the nonregular LTPA group. After the separation of men and women, significant differences were observed between regular LTPA and nonregular LTPA groups in underweight participants aged 45- 
49 years, and the nonregular LTPA group had a higher prevalence of underweight (men: 1.10\%; women: $5.40 \%$ ). Moreover, among participants aged 50-54 years, the prevalence of underweight significantly differed between regular LTPA and nonregular LTPA groups. The nonregular LTPA group had a higher prevalence of underweight than the other group (1.60\%). 
Table 3

Comparison between the prevalence of overweight/obesity and LTPA status among middle-aged and older adults in Taiwan

\begin{tabular}{|c|c|c|c|c|}
\hline \multirow{2}{*}{\multicolumn{2}{|c|}{ Variables }} & \multicolumn{2}{|l|}{ LTPA Status } & \multirow[t]{2}{*}{$P$-value } \\
\hline & & Regular LTPA & Non-regular LTPA & \\
\hline \multicolumn{5}{|c|}{ Men $(n=5,502)$} \\
\hline \multirow[t]{4}{*}{$45-49$} & Underweight & $0(00.00 \%)$ & 7(01.10\%) & $0.004^{*}$ \\
\hline & Normal weight & $76(38.60 \%)$ & $262(39.50 \%)$ & \\
\hline & Overweight & $47(23.90 \%)$ & $221(33.30 \%)$ & \\
\hline & Obesity & $74(37.60 \%)$ & $174(26.20 \%)$ & \\
\hline \multirow[t]{4}{*}{$50-54$} & Underweight & $0(00.00 \%)$ & $10(01.60 \%)$ & $0.001^{*}$ \\
\hline & Normal weight & $98(40.80 \%)$ & $232(37.10 \%)$ & \\
\hline & Overweight & $105(43.80 \%)$ & $223(35.60 \%)$ & \\
\hline & Obesity & $37(15.40 \%)$ & $161(25.70 \%)$ & \\
\hline \multirow[t]{4}{*}{$55-59$} & Underweight & $3(01.40 \%)$ & $13(01.80 \%)$ & 0.170 \\
\hline & Normal weight & $76(36.40 \%)$ & $312(43.40 \%)$ & \\
\hline & Overweight & $90(43.10 \%)$ & $251(34.90 \%)$ & \\
\hline & Obesity & $40(19.10 \%)$ & $143(19.90 \%)$ & \\
\hline \multirow[t]{4}{*}{$60-64$} & Underweight & $0(00.00 \%)$ & $15(02.20 \%)$ & 0.127 \\
\hline & Normal weight & $100(45.70 \%)$ & $294(44.00 \%)$ & \\
\hline & Overweight & $85(38.80 \%)$ & $242(36.20 \%)$ & \\
\hline & Obesity & $34(15.50 \%)$ & $117(17.50 \%)$ & \\
\hline \multirow[t]{4}{*}{$\geq 65$} & Underweight & $3(00.60 \%)$ & $35(02.40 \%)$ & 0.062 \\
\hline & Normal weight & $219(46.40 \%)$ & $728(48.90 \%)$ & \\
\hline & Overweight & 177(37.50\%) & $505(33.90 \%)$ & \\
\hline & Obesity & $73(15.50 \%)$ & $220(14.80 \%)$ & \\
\hline \multicolumn{5}{|c|}{ Women $(n=6,153)$} \\
\hline $45-49$ & Underweight & $11(05.30 \%)$ & $45(05.40 \%)$ & $0.003^{*}$ \\
\hline \multicolumn{5}{|c|}{ Abbreviation: LTPA, leisure time physical activity } \\
\hline${ }^{\star} p<0.0$ & & & & \\
\hline
\end{tabular}




\begin{tabular}{|c|c|c|c|c|}
\hline \multicolumn{2}{|c|}{ Variables } & \multicolumn{2}{|l|}{ LTPA Status } & \multirow[t]{2}{*}{$P$-value } \\
\hline & & Regular LTPA & Non-regular LTPA & \\
\hline & Normal weight & 149(71.30\%) & $553(66.00 \%)$ & \\
\hline & Overweight & $44(21.10 \%)$ & $151(18.00 \%)$ & \\
\hline & Obesity & $5(02.40 \%)$ & $89(10.60 \%)$ & \\
\hline \multirow[t]{4}{*}{$50-54$} & Underweight & $6(02.80 \%)$ & $52(05.70 \%)$ & 0.077 \\
\hline & Normal weight & $146(67.60 \%)$ & $538(59.10 \%)$ & \\
\hline & Overweight & $45(20.80 \%)$ & $215(23.60 \%)$ & \\
\hline & Obesity & $19(08.80 \%)$ & $106(11.60 \%)$ & \\
\hline \multirow[t]{4}{*}{$55-59$} & Underweight & $7(03.60 \%)$ & $40(04.40 \%)$ & 0.131 \\
\hline & Normal weight & $136(69.00 \%)$ & $542(60.20 \%)$ & \\
\hline & Overweight & $36(18.30 \%)$ & $225(25.00 \%)$ & \\
\hline & Obesity & $18(09.10 \%)$ & $93(10.30 \%)$ & \\
\hline \multirow[t]{4}{*}{$60-64$} & Underweight & $6(03.00 \%)$ & $27(03.50 \%)$ & 0.704 \\
\hline & Normal weight & $125(63.10 \%)$ & $460(59.80 \%)$ & \\
\hline & Overweight & $48(24.20 \%)$ & $187(24.30 \%)$ & \\
\hline & Obesity & $19(09.60 \%)$ & $95(12.40 \%)$ & \\
\hline \multirow[t]{4}{*}{$\geq 65$} & Underweight & $17(05.30 \%)$ & $63(04.00 \%)$ & 0.404 \\
\hline & Normal weight & 164(51.10\%) & $881(55.30 \%)$ & \\
\hline & Overweight & $93(29.00 \%)$ & $449(28.20 \%)$ & \\
\hline & Obesity & $47(14.60 \%)$ & $201(12.60 \%)$ & \\
\hline \multicolumn{5}{|c|}{ Pooled $(n=11,655)$} \\
\hline \multirow[t]{4}{*}{$45-49$} & Underweight & $11(02.70 \%)$ & $52(03.50 \%)$ & 0.556 \\
\hline & Normal weight & $225(55.40 \%)$ & $815(54.30 \%)$ & \\
\hline & Overweight & $91(22.40 \%)$ & $372(24.80 \%)$ & \\
\hline & Obesity & $79(19.50 \%)$ & $262(17.50 \%)$ & \\
\hline $50-54$ & Underweight & $7(01.50 \%)$ & $62(04.00 \%)$ & $0.001^{*}$ \\
\hline \multicolumn{5}{|c|}{ Abbreviation: LTPA, leisure time physical activity } \\
\hline$\star p<0$ & & & & \\
\hline
\end{tabular}




\begin{tabular}{|c|c|c|c|c|}
\hline \multicolumn{2}{|c|}{ Variables } & \multicolumn{2}{|l|}{ LTPA Status } & \multirow[t]{2}{*}{$P$-value } \\
\hline & & Regular LTPA & Non-regular LTPA & \\
\hline & Normal weight & $243(53.40 \%)$ & $769(50.10 \%)$ & \\
\hline & Overweight & 150(33.00\%) & $438(28.50 \%)$ & \\
\hline & Obesity & $55(12.10 \%)$ & $267(17.40 \%)$ & \\
\hline \multirow[t]{4}{*}{$55-59$} & Underweight & $10(02.50 \%)$ & $53(03.30 \%)$ & 0.801 \\
\hline & Normal weight & $213(52.30 \%)$ & $855(52.80 \%)$ & \\
\hline & Overweight & $126(31.00 \%)$ & $476(29.40 \%)$ & \\
\hline & Obesity & $58(14.30 \%)$ & $236(14.60 \%)$ & \\
\hline \multirow[t]{4}{*}{$60-64$} & Underweight & $6(01.40 \%)$ & $42(02.90 \%)$ & 0.239 \\
\hline & Normal weight & $226(54.20 \%)$ & $754(52.50 \%)$ & \\
\hline & Overweight & $132(31.70 \%)$ & $429(29.90 \%)$ & \\
\hline & Obesity & $53(12.70 \%)$ & $212(14.80 \%)$ & \\
\hline \multirow[t]{4}{*}{$\geq 65$} & Underweight & $19(02.40 \%)$ & $97(03.10 \%)$ & 0.104 \\
\hline & Normal weight & $383(48.30 \%)$ & $1609(52.20 \%)$ & \\
\hline & Overweight & $271(34.20 \%)$ & $953(30.90 \%)$ & \\
\hline & Obesity & $120(15.10 \%)$ & $421(13.70 \%)$ & \\
\hline \multicolumn{5}{|c|}{ Abbreviation: LTPA, leisure time physical activity } \\
\hline \multicolumn{4}{|c|}{${ }^{\star} p<0.05$} & \\
\hline
\end{tabular}

Table 4 presents the results of multivariate regression for regular LTPA and BMI scores. The results indicated a positive relationship between regular LTPA and BMI scores $(\beta=0.021, p<0.05)$ in Model 1 . More regular LTPA translated to higher BMI scores. However, after adjustment for age, gender, selfreported health status, occupation, and education, no significant differences were found between regular LTPA and BMI scores $(p=0.108)$. 
Table 4

Multivariate regression for regular LTPA to BMI scores

\begin{tabular}{|c|c|c|c|c|c|c|}
\hline \multirow[t]{2}{*}{ Variables } & \multicolumn{3}{|c|}{ Model 1 (unadjusted) } & \multicolumn{3}{|c|}{ Model 2 (adjusted $\left.{ }^{a}\right)$} \\
\hline & $\beta$ & SE & P-value & $\boldsymbol{\beta}$ & SE & P-value \\
\hline Regular LTPA & 0.021 & 0.069 & $0.022^{*}$ & 0.015 & 0.068 & 0.108 \\
\hline Non-regular LTPA & Ref. & - & - & Ref. & - & - \\
\hline \multicolumn{7}{|c|}{ Abbreviations: LTPA, leisure time physical activity; BMI: body mass index; SE, standard erro } \\
\hline \multicolumn{7}{|l|}{${ }^{\star} p<0.05$} \\
\hline
\end{tabular}

The results of the multivariate logistic regression for regular LTPA and obesity, overweight, and underweight risk are shown in Table 5. Irrespective of adjustment for age, gender, self-reported health status, occupation, and education, a significant and negative relationship was observed between regular LTPA and underweight (Model 1: OR $=0.638$, Model 2: $\mathrm{OR}=0.713, p<0.05$ ).

Table 5

Multivariate logistic regression for regular LTPA and the risk of obesity, overweight, and underweight

\begin{tabular}{|c|c|c|c|c|c|c|}
\hline \multirow[t]{2}{*}{ Variables } & \multicolumn{2}{|c|}{ Model 1 (unadjusted) } & \multicolumn{4}{|c|}{ Model 2 (adjusted $^{\mathrm{a}}$ ) } \\
\hline & OR & $95 \% \mathrm{Cl}$ & $P$-value & OR & $95 \% \mathrm{Cl}$ & $P$-value \\
\hline \multicolumn{7}{|l|}{ Obesity } \\
\hline Regular LTPA & 1.035 & $0.913-1.173$ & 0.590 & 0.985 & $0.862-1.125$ & 0.822 \\
\hline Non-regular LTPA & Ref. & - & - & Ref. & - & - \\
\hline \multicolumn{7}{|l|}{ Overweight } \\
\hline Regular LTPA & 1.076 & $0.972-1.190$ & 0.157 & 1.046 & $0.941-1.162$ & 0.403 \\
\hline Non-regular LTPA & Ref. & - & - & Ref. & - & - \\
\hline \multicolumn{7}{|l|}{ Underweight } \\
\hline Regular LTPA & 0.638 & $0.474-0.859$ & $0.003^{*}$ & 0.713 & $0.527-0.965$ & $0.028^{*}$ \\
\hline Non-regular LTPA & Ref. & - & - & Ref. & - & - \\
\hline \multicolumn{7}{|c|}{ Abbreviations: $\mathrm{Cl}$, confidence interval; LTPA, leisure time physical activity; OR, odds ratio } \\
\hline$\star p<0.05$ & & & & & & \\
\hline
\end{tabular}




\section{Discussion}

To our knowledge, this is the first study to recruit middle-aged and older adults without regular LTPA by considering variety in gender, obesity status, health status, education, and occupation factors in Taiwan. The main findings of this study were as follows: (1) regular LTPA was associated with a reduced risk of underweight among middle-aged and older adults; and (2) in adults who performed regular LTPA, a higher proportion of them had normal weight, and excellent or good self-reported health status, and these adults had a lower rate of underweight compared with those with nonregular LTPA. These findings suggest that regular LTPA may maintain or promote a symmetric figure and perceived good health status as well as reduce the risk of underweight among middle-aged and elderly adults.

The associations of demographic variables such as age, gender, income, and residential location with PA have been reported [15]. For example, the proportion of physical inactivity is higher in women than in men ( $40 \%$ vs. $28 \%$ ), and physical inactivity more common in high-income countries than in low-income countries ( $45 \%$ vs. $25 \%$ ) and more prevalent in the Americas than in Southeast Asia (43\% vs. $17 \%$ ) [8]. In the present study, regular LTPA was associated with male sex (53\%), normal weight (49\%), college education (27\%), and being retired (35\%), and $76 \%$ of the participants reported excellent or good selfreported health status.

ACSM suggested that both moderate- and vigorous-intensity PA (for $\geq 150 \mathrm{~min} /$ week and $\geq 75$ $\mathrm{min} /$ week, respectively) had beneficial effects on weight management and reduced the risk of chronic diseases, cognitive impairment, disability, and premature mortality $[4,5,14]$. Hallal et al. reported that the participation of adults in moderate- and vigorous-intensity PA decreased with age [8]. In the present study, we observed that only $21 \%$ of middle-aged and elderly adults performed regular LTPA in Taiwan. Notably, the proportion of regular LTPA among adults increased with age, from 16-18\% among middle-aged adults to $33 \%$ among elderly adults. A similar study reported that PA levels generally decrease with age, whereas an improvement in regular PA was observed as adults reached retirement age ( $\geq 65$ years) [16]. Future research should investigate whether an internal or external motivation (e.g., healthy concept enhancement, national policy development, economic pressure release, and sociocultural change) for adults promotes regular LTPA during at retirement age.

A study reported that BMI was significantly associated with dependency during activities of daily living in elderly individuals and that this dependency decreased in the presence of LTPA. Moreover, no significant interaction was noted between BMI and LTPA with regard to their association with dependency in activities of daily living, which indicates substantial confounding effects between BMI and LTPA [17]. In this study, we found that regular LTPA was associated with BMI among middle-aged and elderly adults but became nonsignificant after adjustment for confounding factors such as age, gender, self-reported health status, occupation, and education. Confounding factors may overestimate or underestimate the real magnitude of an association or even change the direction of a real association [18]. Therefore, the use of properly adjusted confounding factors is necessary to avoid bias and distortion. 
Notably, previous studies have indicated that underweight was associated with increased all-cause mortality compared with normal weight $[19,20]$. This high mortality among individuals with underweight may be attributable to smoking, preexisting illness, and increased risk of injury and impaired survival after an accident [19]. In the current study, we observed that regular LTPA was associated with a reduced risk of underweight $\left(B M I<18.5 \mathrm{~kg} / \mathrm{m}^{2}\right)$. Compared with nonregular LTPA, regular LTPA was associated with a lower prevalence of underweight in men (aged 45-54 years) and women (aged 45-49 years). A study reported a significant correlation between PA and muscle mass among young and older adults [21, 22]. Sagiv et al. indicated that regular PA reduced height loss due to aging in both men and women [23]. Therefore, we speculate that regular LTPA may promote muscle mass and bone health and prevent height loss $[14,23]$, resulting in an optimization in BMI and prevention of underweight among middle-age adults.

The present study has some limitations. First, this study did not measure the body fat percentage, muscle mass, and bone mineral density of the participants. Without these measurements, it may be difficult to comprehensively elucidate the mechanisms underlying the reduction of the risk of underweight by regular LTPA. Second, our questionnaire did not include the reason for participation in regular LTPA by the participants; thus, the motivation behind the improved and regular LTPA observed among adults during retirement age remains unclear.

\section{Conclusions}

This study demonstrated that regular LTPA was associated with a reduced risk of underweight among middle-aged and elderly adults. Regular LTPA showed no relationship with BMI and obesity after adjustment for confounding factors (e.g., age, gender, and occupation). Further research on the association between regular LTPA, body fat percentage, and bone mineral density in Taiwanese adults is warranted.

\section{Abbreviations}

ACSM: American College of Sports Medicine; BMI: Body mass index; CATI: two-month telephone interview; Cl: confidence interval; LTPA: Leisure-time physical activity; OR: odds ratio; PA: physical activity; SD: standard deviation; TNPAS: Taiwan's National Physical Activity Survey.

\section{Declarations}

\section{Acknowledgments}

This study was based on data from the National Physical Fitness Survey in Taiwan provided by the Sports Cloud: Information and Application Research Center of Sports for All, Sport Administration, Ministry of Education in Taiwan. The interpretation and conclusions contained herein do not represent those of the Sport Administration, Ministry of Education in Taiwan. 
YTC participated in the design, conducted the statistical analyses, interpreted the data, and drafted the manuscript. PFL and CFL helped in conducting the study and revising the manuscript. AC and YCC helped to manage and analyze the data. $\mathrm{CCH}$ supervised the study and critically reviewed and revised the manuscript. All authors read and approved the final manuscript.

\section{Funding}

This study was under three years of an integrated research project, which mainly supported by the Ministry of Science and Technology in Taiwan (MOST 105-2627-M-030-002, 106-2627-M-030-002, 1072627-M-030-002, 109-2410-H-030-059). The MOST provided financial supports, including the costs of the project. Besides, the cost of data analysis was supported by the Ministry of Education of Taiwan (FJUA0108153).

\section{Availability of data and material}

The data that support the findings of this study are available from [the Sports Cloud: Information and Application Research Center of Sports for All, Sport Administration, Ministry of Education in Taiwan] but restrictions apply to the availability of these data, which were used under license for the current study, and so are not publicly available. Data are however available from the authors upon reasonable request and with permission of [the Sports Cloud: Information and Application Research Center of Sports for All, Sport Administration, Ministry of Education in Taiwan].

\section{Ethics approval and consent to participate}

This study was conducted with a secondary database provided by the Sports Cloud: Information and Application Research Center of Sports for All, Sport Administration, Ministry of Education in Taiwan. All consents obtained from the study participants were written prior the data collection. This study's design and analysis procedure was approved by the Ethical Committee of Fu Jen Catholic University (FJU-IRBC108088).

\section{Consent for publication}

Not applicable.

\section{Consent for publication}

Participants were provided a study overview and oral consent was attained.

\section{Competing interests}

The authors declare that they have no competing interests.

\section{Author details}


${ }^{1}$ Department of Athletic Performance, National Taiwan Normal University, Taipei City 106, Taiwan. ${ }^{2}$ Department of Leisure Industry and Health Promotion, National Ilan University, Yilan County 260, Taiwan. ${ }^{3}$ Department of Physical Education and Sport Science, National Taiwan Normal University, Taipei City 106, Taiwan. ${ }^{4}$ Air Permits Division, Texas Commission on Environmental Quality, PO Box 13087 Austin, Texas, USA. ${ }^{5}$ Center of General Education, Taipei Medical University, Taipei 11031, Taiwan. ${ }^{6}$ Department of Physical Education, Fu Jen Catholic University, New Taipei City 24205, Taiwan. ${ }^{7}$ Research and Development Center for Physical Education, Health and Information Technology, College of Education, Fu Jen Catholic University, New Taipei City 24205, Taiwan. ${ }^{8}$ Office of Physical Education, Fu Jen Catholic University, New Taipei City 24205, Taiwan.

\section{References}

1. Lim HJ, Xue H, Wang Y. Global trends in obesity. Handbook of Eating and Drinking: Interdisciplinary Perspectives 2020, 1217-1235.

2. Stiegler P, Cunliffe A. The Role of Diet and Exercise for the Maintenance of Fat-Free Mass and Resting Metabolic Rate During Weight Loss. Sports medicine. 2006;36:239-62. doi:10.2165/00007256-200636030-00005.

3. Gurrici S, Hartriyanti Y, Hautvast J, Deurenberg P. Relationship between body fat and body mass index: differences between Indonesians and Dutch Caucasians. Eur J Clin Nutr. 1998;52:779-83. doi:10.1038/sj.ejcn.1600637.

4. DONNELLY JE, BLAIR SN, JAKICIC JM, MANORE MM, RANKIN JW, SMITH BK. Appropriate Physical Activity Intervention Strategies for Weight Loss and Prevention of Weight Regain for Adults. Med Sci Sports Exerc. 2009;41:459-71. doi:10.1249/MSS.0b013e3181949333.

5. Garber CE, Blissmer B, Deschenes MR, Franklin BA, Lamonte MJ, Lee IM, Nieman DC, Swain DP. American College of Sports, M. American College of Sports Medicine position stand. Quantity and quality of exercise for developing and maintaining cardiorespiratory, musculoskeletal, and neuromotor fitness in apparently healthy adults: guidance for prescribing exercise. Med Sci sports Exerc. 2011;43:1334-59. doi:10.1249/MSS.0b013e318213fefb.

6. JAKICIC JM, CLARK K, COLEMAN E, DONNELLY JE, FOREYT J, MELANSON E, VOLEK J, VOLPE SL. Appropriate Intervention Strategies for Weight Loss and Prevention of Weight Regain for Adults. Med Sci Sports Exerc. 2001;33:2145-56.

7. Hall G, Laddu DR, Phillips SA, Lavie CJ, Arena R. A tale of two pandemics: How will COVID-19 and global trends in physical inactivity and sedentary behavior affect one another? Prog Cardiovasc Dis. 2021;64:108-10. doi:https://doi.org/10.1016/j.pcad.2020.04.005.

8. Hallal PC, Andersen LB, Bull FC, Guthold R, Haskell W, Ekelund U. Global physical activity levels: surveillance progress, pitfalls, and prospects. The Lancet. 2012;380:247-57. doi:https://doi.org/10.1016/S0140-6736(12)60646-1. 
9. Lin Y-Y, Huang C-S. Aging in Taiwan: Building a Society for Active Aging and Aging in Place. Gerontologist. 2015;56:176-83. doi:10.1093/geront/gnv107.

10. Lin Y-T, Chen M, Ho C-C, Lee T-S. Relationships among Leisure Physical Activity, Sedentary Lifestyle, Physical Fitness, and Happiness in Adults 65 Years or Older in Taiwan. International Journal of Environmental Research Public Health. 2020;17:5235.

11. National Development Council. Population Projections for the Republic of China (Taiwan): 20182065. Available online: https://www.ndc.gov.tw/en/cp.aspx?n=2E5DCB04C64512CC (accessed on 30 May).

12. Rowe JW, Kahn RL, Successful aging. Gerontologist 1997, 37, 433-440, doi:10.1093/geront/37.4.433.

13. Kim J, Lee S, Chun S, Han A, Heo J. The effects of leisure-time physical activity for optimism, life satisfaction, psychological well-being, and positive affect among older adults with loneliness. Annals of Leisure Research. 2017;20:406-15. doi:10.1080/11745398.2016.1238308.

14. Chodzko-Zajko W, Schwingel A, Chae Hee P. Successful Aging: The Role of Physical Activity. American Journal of Lifestyle Medicine. 2008;3:20-8. doi:10.1177/1559827608325456.

15. Mummery W, Kolt G, Schofield G, McLean G. Associations between physical activity and other lifestyle behaviors in older New Zealanders. Journal of Physical Activity Health. 2007;4:412-23.

16. Caspersen CJ, Pereira MA, Curran KM. Changes in physical activity patterns in the United States, by sex and cross-sectional age. Medicine \& Science in Sports \& Exercise 2000, 32.

17. Simoes EJ, Kobau R, Kapp J, Waterman B, Mokdad A, Anderson L. Associations Of Physical Activity And Body Mass Index With Activities Of Daily Living In Older Adults. J Community Health. 2006;31:453-67. doi:10.1007/s10900-006-9024-6.

18. Arija V, Abellana R, Ribot B, Ramón JM. Biases and adjustments in nutritional assessments from dietary questionnaires. Nutr Hosp. 2015;31 Supp/ 3:113-8. doi:10.3305/nh.2015.31.sup3.8759.

19. Roh L, Braun J, Chiolero A, Bopp M, Rohrmann S, Faeh D, for the Swiss National Cohort Study, G. Mortality risk associated with underweight: a census-linked cohort of 31,578 individuals with up to 32 years of follow-up. BMC Public Health 2014, 14, 371, doi:10.1186/1471-2458-14-371.

20. Flegal KM, Graubard BI, Williamson DF, Gail MH. Excess Deaths Associated With Underweight, Overweight, and Obesity. JAMA. 2005;293:1861-7. doi:10.1001/jama.293.15.1861.

21. Baumgartner RN, Waters DL, Gallagher D, Morley JE, Garry PJ. Predictors of skeletal muscle mass in elderly men and women. Mech Ageing Dev. 1999;107:123-36. doi:https://doi.org/10.1016/S00476374(98)00130-4.

22. Proctor DN, Melton lii LJ, Khosla S, Crowson CS, O'Connor MK, Riggs BL. Relative Influence of Physical Activity, Muscle Mass and Strength on Bone Density. Osteoporos Int. 2000;11:944-52. doi:10.1007/s001980070033.

23. Sagiv M, Vogelaere PP, Soudry M, Ehrsam R. Role of Physical Activity Training in Attenuation of Height Loss through Aging. Gerontology. 2000;46:266-70. doi:10.1159/000022170. 